\title{
Simple, fast and inexpensive method for determination of ranitidine hydrochloride based on conductometric measurements
}

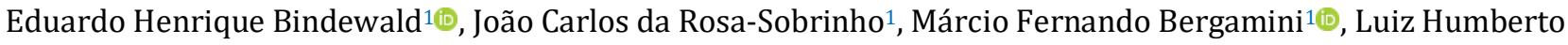 \\ Marcolino-Júnior ${ }^{1+(B)}$ \\ ${ }^{1}$ Laboratório de Sensores Eletroquímicos - LabSensE - Universidade Federal do Paraná -UFPR - Curitiba-PR, Brazil \\ + Corresponding author: Luiz Humberto Marcolino-Júnior, e-mail address: luiz1berto@ufpr.br
}

\section{ARTICLE INFO}

Article history:

Received: March 5, 2018

Accepted: November 2, 2018

Published: December 5, 2018

\author{
Keywords: \\ 1. ranitidine hydrochloride \\ 2. quality control \\ 3. conductometric determination
}

\begin{abstract}
This work aims the development and optimization of an alternative method for ranitidine hydrochloride (RAN-HCl) determination. The proposed method was based on conductometric titration of $\mathrm{RAN}$ by precipitation of $\mathrm{AgCl}$ solid using a solution of $\mathrm{AgNO}_{3}$ as titrant. It was investigated the possibility of performing the titrations on hydroalcoholic and deionized water medium. A limit of detection of $1.0 \mathrm{mmol} \mathrm{L}^{-1}$ and $0.5 \mathrm{mmol} \mathrm{L}^{-1}$ were achieved for RAN titration in deionized water and in a 75:25 hydroalcoholic mixture, respectively. Such behavior is attributed to the dielectric constant of hydroalcoholic medium, which is lower than aqueous solution, making $\mathrm{AgCl}$ more insoluble and improving the resolution of the conductivity curve around the end point. Therefore, it is concluded that the conductometric titration method to determine RAN using $\mathrm{AgNO}_{3}$ as titrant proved to be feasible at low drug concentrations. The statistical calculations for obtained results suggested good precision for the conductometric method. According to t-test, there were no significant differences between found values at a $95 \%$ confidence level. Moreover, obtained results showed an excellent performance of the proposed method on quality control of RAN-HCl in generic formulations without any sample pretreatment.

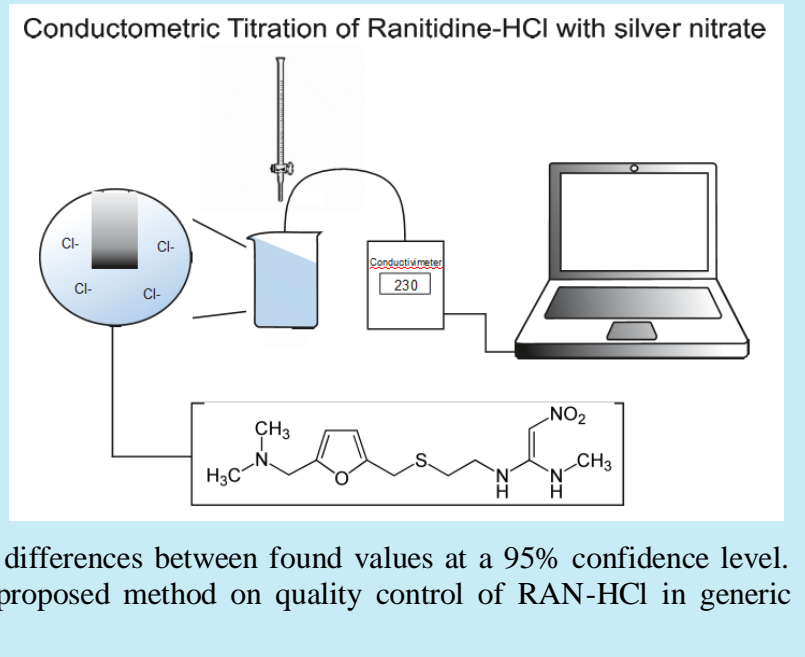

\section{Introduction}

In recent years, studies indicate that about $10 \%$ of the world population will suffers lesions in the gastric mucous membranes or in the duodenum ${ }^{1}$. The more effective treatment of this type of lesion is based on mainly administration of drugs proton pump inhibitors, as omeprazole $2 /$ pantoprazole $^{3}$ or anti-histamine which ranitidine hydrochloride could be highlighted ${ }^{4}$. Ranitidine hydrochloride (RAN-HCl - Figure 1) plays in the organism action inhibiting the secretion of gastric acid, reducing both volume and content of acid and pepsin secretion ${ }^{5}$. This drug is largely commercialized around the world and consequently the development of feasible, fast and sensitive methods for pharmaceutical quality control is very important.<smiles>CCN/C(=C/[N+](=O)[O-])NCCSCc1ccc(CN(C)C)o1</smiles>

Figure 1. Molecular structure of ranitidine hydrochloride. 
There are several procedures reported in literature for ranitidine determination based on chromatographic $^{6,7}, \mathrm{UV}$-Vis spectroscopy ${ }^{8-10}$ and voltammetric methods ${ }^{11-13}$. British Pharmacopeia ${ }^{14}$ describes the dosage of $\mathrm{RAN}-\mathrm{HCl}$ in pharmaceutical formulations for quality control by liquid chromatography using potassium dihydrogen phosphate buffer and acetonitrile as mobile phase with UV detection. Brazilian Pharmacopeia $^{15}$ suggests direct molecular absorption spectrophotometry with detection at $314 \mathrm{~nm}$ as official method for determination of ranitidine hydrochloride. These cited methodologies are very reliable and exhibit sensibility, precision and accuracy adequate for concentration levels of pharmaceuticals formulations of RAN-HCl. However, these techniques demand long-time for sample preparation/treatment, use large volumes of organic solvents and/or require sophisticated and expensive instruments.

In order to overcome the drawbacks showed by other techniques, titrimetric procedures are an interesting alternative way for analysis of pharmaceutical formulations and/or biological samples, since this type of methodology is rather simple, with fast response and low-cost instrumentation. Moreover, detection of end point can be performed using an instrumental technique which is a practical approach to minimize analyst errors and leads more rapid, precise and accurate results ${ }^{16}$.

Several "hydrochlorides" such as RAN-HCl can be found as active ingredients in commercialized pharmaceutical formulations. In general, hydrochlorides are more water-soluble and provide better absorption by human body ${ }^{17}$. Some methodologies have been described for determination of these compounds, based on indirect quantification of drug based on chloride ions released from salt dissolution ${ }^{18-21}$. Caetano et al. ${ }^{18}$ reported a low-cost conductometric method for determination of verapamil hydrochloride in pharmaceutical formulations based on chloride ions released from verapamil hydrochloride which were titrated with an aqueous solution of silver nitrate. Similar approach was adopted by Noronha et $a l^{19}$ who described potentiometric and conductometric titration of diltiazem hydrochloride (DTZ) determination based on the chemical reaction between chloride ions coming from diltiazem hydrochloride molecule and $\mathrm{Ag}(\mathrm{I})$ ions, yielding the precipitate $\mathrm{AgCl}$ solid. The limit of applicability of the conductometric method based on precipitation titration is defined by solubility of solid yielded $\mathrm{AgCl}\left(\mathrm{Kps} \sim 1.8 \times 10^{-10}\right.$ ). The solubility product constant can be affected by alteration in the dielectric constant of the solvent (ع) allowing to use lower concentration level of reagents. A decrease in the Kps could be obtained simply using of hydroalcoholic medium which presents a minor value of dielectric constant when compared to aqueous solution. This effect plays an important role in the precipitation titration procedure allowing the use of lower quantity of reagents.

Based on above-cited information, the present work describes a practical and accurate methodology for RAN hydrochloride determination based on conductometric titration of chloride ions using by $\mathrm{AgNO}_{3}$ as titrant in hydroalcoholic medium.

\section{Materials and methods}

\subsection{Instruments, reagents and chemicals}

A system comprising by Conductometer Oakton ${ }^{\circledR}$ COM 500 and a classic burette of $25.0 \mathrm{~mL}$ associated with a magnetic stirrer were used for all conductometric measurements. The solutions were prepared with deionized water obtained from MilliQ system or ethanol (Carlo Erba, 99.9\%). Other used reagents were silver nitrate and sodium chloride (Merck, > 99\% content) and ranitidine hydrochloride (Aldrich, > 95\% content).

Silver nitrate solutions were used in the titration of the same concentration of ranitidine solutions ranging from 0.10 to $1.0 \times 10^{-3} \mathrm{~mol} \mathrm{~L}^{-1}$. The same were standardized using anhydrous sodium chloride as primary standard. For comparative method, a spectrophotometer Hewlett Packard, model $8452 \mathrm{~A}$ equipped with $1.0 \mathrm{~cm}$ light path quartz cuvette. Acid-base titrations were performed using a $780 \mathrm{pHmeter}$ Metrohm equipped with combined glass electrode associated a classic burette of $25.0 \mathrm{~mL}$ and magnetic stirrer.

\subsection{Samples and standard solutions}

Pharmaceutical samples in tablet form containing ranitidine hydrochloride (RAN-HCl) were purchased in local drugstore. For each sample, twenty tablets were crushed using mortar and pistil and $50.0 \mathrm{~mL}$ of a stock solution with theoretical concentration of $1.0 \mathrm{mmol} \mathrm{L}^{-1}$ was 
prepared using deionized water or hydroalcoholic solution in different proportions of solvent.

\subsection{Conductometric titration}

Aliquots of $10.0 \mathrm{~mL}$ or $5.0 \mathrm{~mL}$ (reference solutions or sample) were transferred to beakers and titrated with solutions of $\mathrm{AgNO}_{3}$ at the same concentration of the analyte (between $5.0 \times 10^{-4}$ to $0.1 \mathrm{~mol} \mathrm{~L}^{-1}$ ) with additions of $0.5 \mathrm{~mL}$ or $1.0 \mathrm{~mL}$. Conductance values were recorded 10 seconds after the titrant addition. Before plotting titration graphs, conductance values were corrected according to volume of titrant added (Equation 1), all titrations were conducted in temperature controlled at $20^{\circ} \mathrm{C}$.

$$
L_{c o r r}=L_{\text {exp }} *\left(\left(V_{i n i}+V_{a d d}\right) / V_{\text {ini }}\right)
$$

where: $\mathrm{L}_{\text {corr }}=$ corrected conductance, $\mathrm{L}_{\exp }=$ experimental conductance, and $\mathrm{V}_{\mathrm{ini}}, \mathrm{V}_{\text {add }}$ the initial volume and added volume, respectively.

From graph of corrected conductance $v s$. volume of $\mathrm{AgNO}_{3}$ solution, the end point was obtained by the intersection of the straight-line segments, and thus determining the concentration of RAN-HCl.

\subsection{Acid-Base titration ( $\mathrm{pH}$ curves)}

A standard solution of RAN-HCl, $0.10 \mathrm{~mol} \mathrm{~L}^{-1}$ was titrated with $\mathrm{NaOH}$ at the same concentration, previously standardized by sodium biphthalate. Based on the $\mathrm{pH}$ vs. $\mathrm{NaOH}$ volume curve was possible to estimate the $\mathrm{pKa}$ of $\mathrm{RAN}-\mathrm{HCl}$. The $\mathrm{pKa}$ value was estimated using the $\mathrm{pH}$ obtained at $1 / 2$ volume of the end point.

\subsection{Comparative method}

Comparative method used is described on Brazilian Pharmacopeia ${ }^{13}$ based on UV-Vis spectroscopy. A portion equivalent to one tablet was dissolved in water and after diluting to concentration around to $0.00125 \%(\mathrm{w} / \mathrm{v})$. Standard solution was prepared at same concentration and the absorbance measurements of samples and standards solution were carry out at $314 \mathrm{~nm}$ using a quartz cuvette.

\section{Results and discussion}

\subsection{Preliminary studies}

Firstly, the potentiality of conductometric titration for proposed determination was investigated in order to show that indirect quantification of RAN-HCl can be realized based on precipitation reaction between $\mathrm{Cl}^{-}$and $\mathrm{Ag}^{+}$ions leading to formation of $\mathrm{AgCl}$. An aliquot of 10.0 $\mathrm{mL}$ of $0.10 \mathrm{~mol} \mathrm{~L}^{-1} \mathrm{RAN}-\mathrm{HCl}$ standard solution was prepared in deionized water and it was titrated with a standardized solution of $\mathrm{AgNO}_{3}$ at the same concentration (Figure 2). Typical conductometric curve for titration of $\mathrm{RAN}-\mathrm{HCl}$ with silver nitrate shows two linear segments with significant difference in the slope. Before the endpoint, no significant variation of conductance values was observed which is attributed to consume of chloride ions by precipitation of $\mathrm{AgCl}$ (solubility, $1.1 \times 10^{-5} \mathrm{~mol} \mathrm{~L}^{-1}$ ) concomitantly with reposition of nitrate ions from $\mathrm{AgNO}_{3}$. Slight variation in conductance observed in this segment can be attributed to exchange of ions with very similar ionic mobility $\left(\mathrm{Cl}^{-} 76.3 \mathrm{~S} \mathrm{~cm}^{2} \mathrm{~mol}^{-1}\right.$ and $\mathrm{NO}_{3}{ }^{-} 71.5$ $\mathrm{S} \mathrm{cm}^{2} \mathrm{~mol}^{-1}$ ). After the endpoint, a marked increase of conductance values was observed due to excess of silver and nitrate ions in solution. The endpoint was determined by intersection of segment \#1 and \#2 and RAN-HCl concentration was estimated based on 1:1 stoichiometric relationship.

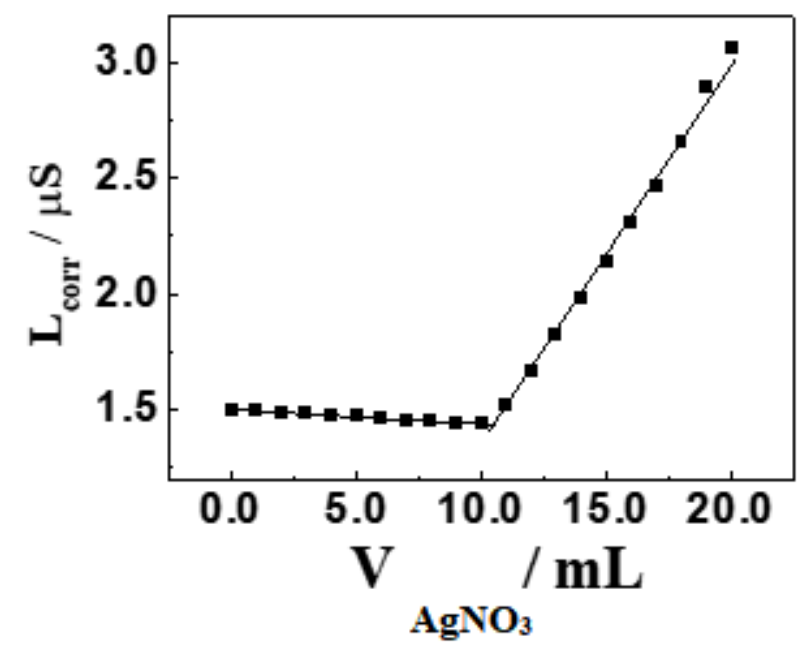

Figure 2. Representative conductometric curve obtained for titration of $10.0 \mathrm{~mL}$ of $0.10 \mathrm{~mol} \mathrm{~L}^{-1} \mathrm{RAN}$ $\mathrm{HCl}$ standard aqueous solution with a standardized solution of $\mathrm{AgNO}_{3} 0.10 \mathrm{~mol} \mathrm{~L}-1$. 
The proposed procedure is based on determination of chloride ions released from RAN$\mathrm{HCl}$ after its dissolution (RAN-HCl(s) $+\mathrm{H}_{2} \mathrm{O} \rightarrow$ $\left.\mathrm{RAN}(\mathrm{aq})+\mathrm{H}_{3} \mathrm{O}^{+}(\mathrm{aq})+\mathrm{Cl}^{-}(\mathrm{aq})\right)$. Potentiometric titration of $\mathrm{RAN}-\mathrm{HCl}$ with $\mathrm{NaOH}$ standard solution was performed in order to verify adequate reactions that occur during the conductometric titration. In Figure $3 \mathrm{~A}$ is possible to observe a curve with similar shape to obtained titration for systems composed by weak acid titrated with strong base (endpoint is observed at $\mathrm{pH}>7.0$ ). Additionally, from titration curve the $\mathrm{pKa}$ value for reaction $\mathrm{RAN}-\mathrm{H}^{+}+\mathrm{H}_{2} \mathrm{O} \leftrightarrows \mathrm{RAN}+\mathrm{H}_{3} \mathrm{O}^{+}$was estimated as $8.05 \pm 0.10(n=3)$. Thus, based on these results we believe that reactions involved in the proposed procedure could be better attributed to: RAN$\mathrm{HCl}(\mathrm{s}) \rightarrow \mathrm{RAN}^{-} \mathrm{H}^{+}(\mathrm{aq})+\mathrm{Cl}^{-}(\mathrm{aq})$ (dissolution step) and $\mathrm{Ag}^{+}(\mathrm{aq})+\mathrm{Cl}^{-}(\mathrm{aq}) \rightarrow \mathrm{AgCl}(\mathrm{s})$ (titration step).

UV-vis spectrophotometric measurements were performed at different $\mathrm{pH}$ values in order to confirm the protonation of ranitidine molecule. Figure 3B shows UV-vis spectra where an increase in the absorption intensity at $310 \mathrm{~nm}$ with the increase of $\mathrm{pH}$ values can be observed. This behavior is attributed to protonation of RAN molecule which is majority form at $\mathrm{pH}$ values at least 2.0 units lower than $\mathrm{pKa}$. These studies confirm that the conductometric titration was performed with RAN molecules in the protonated form.
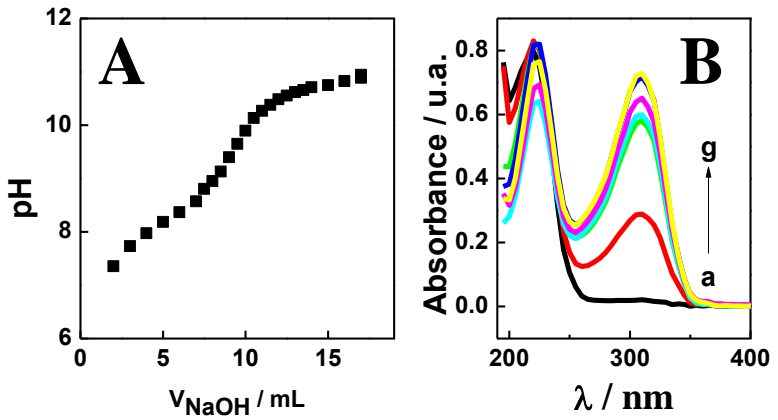

Figure 3. A) pH curve obtained for titration of RAN$\mathrm{HCl}$ using $\mathrm{NaOH}$ standardized solution; B) Absorption spectrum in the UV-Vis region for $\mathrm{RAN}-\mathrm{HCl}$ in $\mathrm{pH}$ values: 1.0 (a), 2.0 (b), 2.5 (c), 3.0 (d), 4.0 (e), 5.0 (f) and $6.0(\mathrm{~g})$

\subsection{Optimization of the titration method}

Several investigations were realized in order to optimize the proposed methodology. For this, all solutions were prepared with deionized water to obtain a lower background signal. Firstly, the effect of solution concentration (titrant and titrated) has been evaluated by performing of three successive titrations using concentrations in range between 0.50 and $10.0 \mathrm{mmol} \mathrm{L}^{-1}$. Table 1 presents results of recovery studies.

Table 1. Titrations realized with deionized water.

\begin{tabular}{|c|c|c|}
\hline $\begin{array}{l}\text { Concentration of ranitidine } \\
\text { added / } \mathrm{mmol} \mathrm{L}^{-1}\end{array}$ & $\begin{array}{l}\text { Concentration of ranitidine } \\
\text { found } / \mathrm{mmol} \mathrm{L}^{-1}\end{array}$ & Recovery \\
\hline 10 & 9.9 & $99 \%$ \\
\hline 1.0 & 0.92 & $92 \%$ \\
\hline 0.50 & - & ND \\
\hline
\end{tabular}

Adequate recoveries values were obtained using solutions with concentration of $10.0 \mathrm{mmol} \mathrm{L}^{-1}$ indicating a well-defined shape of titration curve. When concentrations of $1.0 \mathrm{mmol} \mathrm{L}^{-1}$ were used, a significant decrease in recoveries values were found suggesting a poor profile of the conductometric titration curve. Concentration lower than $1.0 \mathrm{mmol} \mathrm{L}^{-1}$ did not provide a variation in the conductance of solution which did not allow found an end point from titration curve. Thus, the best set of results using aqueous solutions were found only for concentrations higher than $1.0 \mathrm{mmol} \mathrm{L}^{-1}$.
In order to achieve detections below the limit imposed by use of aqueous solution, we decided to try to alter the solubility of solid formed $(\mathrm{AgCl})$ during titration process by using of another solvent mixed on aqueous solutions. The adopted strategy was based on variation of dielectric constant $(\varepsilon)$ of solution. The dielectric constant of a solvent could be related with its polarity and ability for solvation of ions. When a dielectric constant of solvent is higher it means that this solvent is more polar, and it is more efficient to solvate the ions. As consequence of this, an increase in solubility of ionic solid could be observed for solvent with high 
dielectric constant. The dielectric constant of water is $78.3\left(25^{\circ} \mathrm{C}\right)$ and it is higher than ethanol (24); so, a higher solubility of $\mathrm{AgCl}$ solid in water is verified when compared with ethanol. In this way, the use of hydroalcoholic solutions promotes a decrease in the solubility of silver chloride and allows to use of more dilute solutions in the conductometric titration. Titrations employing hydroalcoholic solutions in the range of 0 to $75 \%(\mathrm{v} / \mathrm{v})$ of ethanol were performed using $1.0 \mathrm{mmol} \mathrm{L}^{-1}$ of RAN-HCl and $\mathrm{AgNO}_{3}$ in order to investigate the effect of mix of solvents (Figure 4).

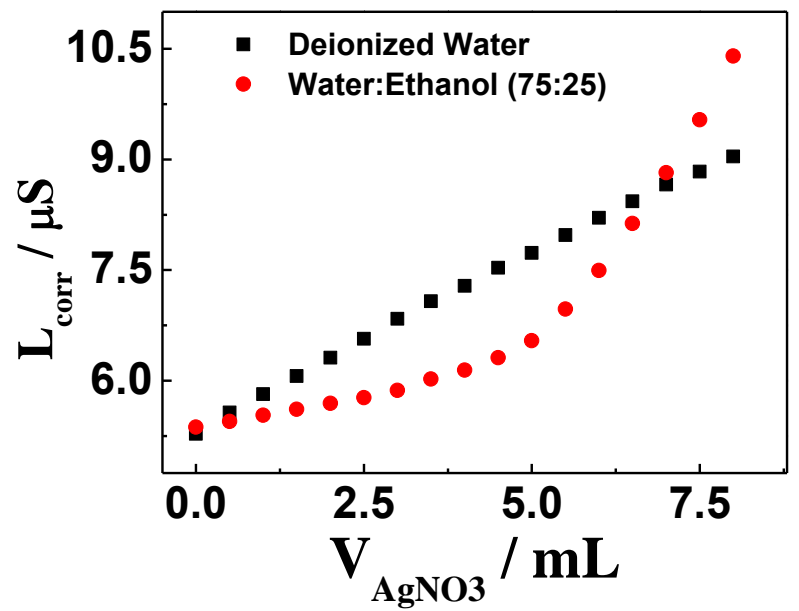

Fig. 4 Titrations conductometric curves obtained using different solvents composition.

By using of hydroalcoholic solutions, recoveries values close to $100 \%$ were obtained for all titrations, indicating that presence of ethanol as solvent results in an improvement in the determination. Amounts of ethanol higher than $50 \%$ did not yield significant differences between the segments of titration curve which can be related with decrease in the solubility of reagents. For larger amounts of alcohol (25:75 water:ethanol) there was a decrease in sensitivity caused by a poor solubility of $\mathrm{AgNO}_{3}$. Using a composition of 75:25 water:ethanol, it was possible to determine the concentration of RAN-HCl employing concentration of $0.5 \mathrm{mmol} \mathrm{L}^{-1}$ for reagent which was not achieved performing the titration in water. Such behavior was attributed to the lower dielectric constant inherent to the solution which resulted in a lower background signal enabling the identification of titration equivalence point with good reliability.

\subsection{Determination of $\mathrm{RAN}-\mathrm{HCl}$ in pharmaceutical samples}

After the optimization of experimental conditions, the proposed method was applied for determination of $\mathrm{RAN}-\mathrm{HCl}$ in triplicate for three different samples of pharmaceutical formulations (Table 2). Results obtained using the conductometric titration were compared with those provided using the spectrophotometric method recommended by the Brazilian Pharmacopoeia and the values given on the pharmaceutical formulations labels.

Table 2. Results of determination of RAN-HCl in pharmaceutical formulations.

\begin{tabular}{|c|c|c|c|c|c|}
\hline & Sample & $\begin{array}{l}\text { Labeled values / } \\
\mathrm{mg}\end{array}$ & $\begin{array}{l}\text { Proposed Method / } \\
\text { mg }\end{array}$ & $\begin{array}{l}\text { Reference Method / } \\
\mathrm{mg}\end{array}$ & RSD* \\
\hline 1 & Generic & 300 & $305 \pm 9$ & $298.4 \pm 0.7$ & $2.1 \%$ \\
\hline 2 & Generic & 150 & $158.7 \pm 0.3$ & $165 \pm 6$ & $3.5 \%$ \\
\hline 3 & Generic & 150 & $161.1 \pm 0.2$ & $163 \pm 5$ & $1.0 \%$ \\
\hline
\end{tabular}

Statistical test suggested good accuracy for the conductometric method in comparison with official methodology, indicating that the excipients used to manufacture the tablets of ranitidine formulations did not exhibit interference in the determination of the drug ${ }^{18-20}$. According to the t-test, there were no significant differences between the values found at the 95\% confidence level. Moreover, results obtained showed an excellent performance of proposed method to quality control of $\mathrm{RAN}-\mathrm{HCl}$ in generic formulations without any sample pretreatment. 


\section{Conclusions}

This study demonstrated that conductometric titration is a very powerful methodology for determination of ranitidine hydrochloride, being a simple, fast and inexpensive alternative route to perform quality control of these species, especially in small laboratories. The use of hydroalcoholic solutions allowed a decrease in the detection limit of the technique. It was possible to perform quality control of RAN-HCl in the order of $0.5 \mathrm{mmol} \mathrm{L}^{-1}$ with significant reducing costs. Pharmaceutical samples without any pretreatment were analyzed using proposed titration and values with excellent agreement with an official method were found.

\section{Acknowledgments}

We gratefully acknowledge financial support from Fundação Araucária, CAPES, and CNPq.

\section{References}

[1] Saul, C., Teixeira, C. R., Pereira-Lima, J. C., Torresini, R. J. S., Redução da prevalência de úlcera duodenal: Um estudo brasileiro (análise retrospectiva na última década: 1996-2005), Arquivos de Gastroenterologia 44 (4) (2007) 320$324 . \quad$ https://doi.org/10.1590/S000428032007000400008

[2] Jorge, S. M. A., Pontinha, A. D. R., OliveiraBrett, A. M., Electrochemical Redox Behavior of Omeprazole Using a Glassy Carbon Electrode, Electroanalysis $22 \quad$ (6) (2010) 625-631. https://doi.org/10.1002/elan.200900377.

[3] Huber, R., Hartmann, M., Bliesath, H., Lühmann, R., Steinijans, V. W., Zech, K. (i), Pharmacokinetics of pantoprazole in man, International Journal of Clinical Pharmacology and Therapeutics, 34 (1 Suppl.) (1996), S7-16. Retrieved from http://europepmc.org/abstract/med/8793599.

[4] De Armas, H. N., Peeters, O. M., Blaton, N., Van Gyseghem, E., Martens, J., Van Haele, G., Van Den Mooter, G., Solid state characterization and crystal structure from $\mathrm{x}$-ray powder diffraction of two polymorphic forms of ranitidine base, Journal of Pharmaceutical Sciences, 98 (1) (2009) 146-158. https://doi.org/10.1002/jps.21395.
[5] Madsen, J. L., Graff, J., Effects of the $\mathrm{H}_{2^{-}}$ receptor antagonist ranitidine on gastric motor function after a liquid meal in healthy humans, Scandinavian Journal of Clinical and Laboratory Investigation 68 (8) (2008) 681-684. https://doi.org/10.1080/00365510802047685.

[6] Arayne, M. S., Sultana, N., Zuberi, M. H., Siddiqui, F. A., Simultaneous determination of metformin, cimetidine, famotidine, and ranitidine in human serum and dosage formulations using HPLC with UV detection, Journal of Chromatographic Science 48 (9) (2010) 721-725. https://doi.org/10.1093/chromsci/48.9.721.

[7] Tatar Ulu, S., Tuncel, M., A sensitive and rapid determination of ranitidine in human plasma by HPLC with fluorescence detection and its application for a pharmacokinetic study, Journal of Chromatographic Science 50 (4) (2012) 301-306. https://doi.org/10.1093/chromsci/bms003.

[8] Cholerton, T. J., Hunt, J. H., Klinkert, G., Martin-Smith, M., Spectroscopic Studies on Ranitidine - its Structure and the Influence of Temperature and $\mathrm{pH}$, Journal of the Chemical Society, Perkin Transactions 24 (11) (1984) 17611766. https://doi.org/10.1039/P29840001761.

[9] Elgailani, I. E. H., Mohammed A. A., Spectrophotometric Determination of Some Antiulcerative Drugs in Pharmaceutical Dosages, Journal of Analytical Chemistry 73 (7) (2018) 679684. https://doi.org/10.1134/S1061934818070079.

[10] de Araújo, W. R., Paixão, T. R. L. C., Amperometric detection of ranitidine using glassy carbon modified with ruthenium oxide hexacyanoferrate adapted in a flow injection system, Electroanalysis 23 (11) (2011) 2549-2554. https://doi.org/10.1002/elan.201100102.

[11] Xi, X., Ming, L., Electrochemical determination of ranitidine hydrochloride in pharmaceutical formulations and biological fluids at graphene modified electrode, Asian Journal of Chemistry $25 \quad$ (10) (2013) 5315-5318. https://doi.org/10.14233/ajchem.2013.14172.

[12] Pınar, P. Talay, Y. Yardım, Z. Şentürk, Electrochemical oxidation of ranitidine at poly (dopamine) modified carbon paste electrode: Its voltammetric determination in pharmaceutical and 
biological samples based on the enhancement effect of anionic surfactant, Sensors and Actuators B: Chemical $273 \quad$ (2018) 1463-1473. https://doi.org/10.1016/j.snb.2018.07.068.

[13] Moldovan, Z., Aboul-Enein, H. Y., Spectrophotometric method for ranitidine determination in drugs using Rhodamine B, Journal of the Chilean Chemical Society 57 (4) (2012) 1422-1427. https://doi.org/10.4067/S071797072012000400018 .

[14] British Pharmacopoeia Commission, Great Britain, Medicines Commission, and General Medical Council (Great Britain). British Pharmacopoeia. Vol II. Ranitidine Hydrochhoride 209 (2000) 5168-5173.

[15] Farmacopéia Brasileira, Vol. II, 5th ed., Agência Nacional de Vigilância Sanitária, Brasília, Brazil 2010, p. 225.

[16] Weber, C., Heuser, M., Mertens, G., Stanjek, H., Determination of clay mineral aspect ratios from conductometric titrations, Clay Minerals 49 (1) (2014) 17-26. https://doi.org/10.1180/claymin.2014.049.1.02.

[17] Allen, L. V., Remington: An Introduction to Pharmacy, Pharmaceutical Press, Retrieved from http://books.google.ca/books?id=J_6H4HfqdJkC.

[18] Caetano, F. R., Gevaerd, A., Bergamini, M. F., Marcolino-Junior, L. H., A Fast and Simple Conductometric Method for Verapamil Hydrochloride Determination in Pharmaceutical Formulations, Current Pharmaceutical Analysis 7 (4) (2011) 275-279. https://doi.org/10.2174/157341211797458041.

[19] de Noronha, B. V., Papi, M. A. P., Bergamini, M. F., Marcolino-Junior, L. H., A Simple and Precise Determination of Diltiazem Hydrochloride by Simultaneous Conductometric and Potentiometric Detection, Current Pharmaceutical $\begin{array}{lllll}\text { Analysis } & 10 & \text { (3) 203-207. }\end{array}$ https://doi.org/10.2174/157341291066614040300 0201.

[20] Sartori, E. R., Suarez, W. T., Fatibello-Filho, O., Determinação condutométrica de cloridrato de metformina em formulações farmacêuticas empregando nitrato de prata como titulante,
Química Nova 32 (7) (2009) 1947-1950. Retrieved from

http://www.scielo.br/scielo.php?script=sci_arttext \&pid=S0100-40422009000700043\&nrm=iso.

[21] Diamandis, E. P., Christopoulos, T. K., Potentiometric titration of pharmaceutical compounds in formulations with sodium tetraphenylborate, Analytica Chimica Acta 152 (C) (1983) 281-284. https://doi.org/10.1016/S00032670(00)84919-3. 